\title{
Challenges faced by SMEs in their digital transformation towards Industry $\mathbf{4 . 0}$
}

\author{
Katarzyna Kowalska \\ Warsaw School of Economics \\ Izabela Kowalik \\ Warsaw School of Economics
}

\section{Introduction}

European economies are driven by more than 25 million SMEs - representing $99.8 \%$ of all EU enterprises ${ }^{1}$. Although they are considered crucial engines for European job creation, growth and wealth, SMEs face continuous uncertainty and a highly-competitive business context in a globalized, turbulent and interconnected world economy. The lack of skills, time, competences and resources in management, financial resources, market information and digital capabilities are only a few examples of the internal and external challenges connected with survival and success in domestic and foreign markets. SMEs also have difficulties in developing new ideas, products and services due to the absence of both knowledge and information about new trends and technologies.

Companies also need to rapidly adopt and incorporate innovative ideas into new products and services. This is especially important in the agri-food and packaging industries, because the nature of this business requires speed, immediacy and dynamism to quickly develop new products, provide them to the consumer and build customer trust and loyalty. Companies are thus looking for agile, co-creative and collaborative tools that will allow them to improve business performance or to develop new products and services. This is why in recent years an increasing number of companies have been using hackathons and other co-creation tools and processes to rapidly implement prototypes, including those that incorporate digital solutions.

1 EASME, Annual Report on European SMEs 2018/2019, European Commission, Brussels 2019. 
The article aims to identify the challenges existing in the process of implementing digital innovations by SMEs, and to describe the new collaboration tools which have the potential to lower the barriers for cross-industry collaboration.

\section{Digital transformation and Industry 4.0}

Taking into account that technology has been completely revolutionizing the present era, and that digital transformation is expected to have a vast impact on almost any every industry, digitalization can bring new opportunities for SMEs by improving the entire value chain ${ }^{2}$.

According to Schallmo et al. digital transformation can be defined as "a framework includes the networking of actors such as businesses and customers across all value-added chain segments and the application of new technologies As such, digital transformation requires skills that involve the extraction and exchange of data as well as the analysis and conversion of that data into actionable information. This information should be used to calculate and evaluate options, in order to enable decisions and/or initiate activities. In order to increase the performance and reach of a company digital transformation involves companies, business models, processes, relationships, products, etc."3.

Ulas ${ }^{4}$ pointed out several driving factors expediting digital transformation, these include, among others, globalization, advancement of technology and innovation, electronic commerce and social media.

Digitalization can be helpful to improve products and/or services, to manage operations in a more efficient way, to reduce costs or to better shape their competitive advantage. According to Chukwunonso and Tukur ${ }^{5}$, the adoption and deployment of new tools and technologies cut down cost and improves efficiency. Moreover, the development of Industry 4.0, artificial intelligence, Internet of Things (IoT), blockchain, cloud computing, augmented reality, 3D Printers, chatbots, Big Data and nanotechnology have been speeding up the process of digitalization. Special attention is being paid to Industry 4.0 which, according to Ulas ${ }^{6}$, is referred to as the fourth

2 P. Kilimis et al., A Survey on Digitalization for SMEs in Brandenburg, Germany, "IFAC-Papers OnLine" 2019, no. 52(13), pp. 2140-2145.

3 D. Schallmo, C. Williams, L. Boardman, Digital Transformation of Business Models-Best Practice, Enabler, and Roadmap, "International Journal of Innovation Management" 2018, no. 21(8), p. 4.

4 D. Ulas, Digital Transformation Process and SMEs, "Procedia Computer Science" 2019, no. 158 , pp. 662-671.

5 F. Chukwunonso, A. Tukur, Problems and prospects of adopting ICT in agriculture, "African Journal of Agricultural Research and Development" 2012, no. 5, pp. 39-47.

6 D. Ulas, Digital Transformation Process... 
industrial revolution, where the manufacturing process is digitalized, machines are directly connected to each other, and personalized manufacturing is possible. Its usage includes digitalization of products and services offered, new market models and digitalization and integration of simple technical - economical relation to complex technical - economical networks ${ }^{7}$. Stoldt et al. ${ }^{8}$ highlight that companies can implement two strategies to digitalize their business - either transform their processes and production sites incrementally or implement radical change by exchanging entire processes and systems with fully digitalized ones. These authors assumed that SMEs do not typically have the economic strength to accomplish such a revolution but are eager to employ novel technologies in their factories to raise their competitiveness.

\section{Challenges faced by SMEs in their digital transformation}

Although digital transformation can bring new opportunities for SMEs and open up new growth paths for development, still many SMEs find it difficult to know in which technologies to invest and how to secure financing for their digital transformation. Peillon and Dubrue ${ }^{9}$ propose a classification of the possible barriers to digitalization for SMEs, these include:

- technical/technological barriers - related to financial limitations, lack of technical resources readily available that could easily upgrade and adopt digital technologies;

- organisational barriers - connected to people's unwillingness to change and the need to change the innovation management of key business operations, products, processes, organisational structures that require new competencies, resources, and collaborations;

- human resource-oriented barriers - linked to lack of qualified employees and lack of digital competences;

- customer-related barriers - associated with customers' fears over a loss of control over information, such as privacy violations, security concerns and security of access to production and corporate systems.

7 F. Zezulka et al., Industry 4.0 - An Introduction in the phenomenon, "IFAC-PapersOnLine" 2016, no. 49(25), pp. 8-12.

8 J. Stoldt et al., Planning for Digitalisation in SMEs using Tools of the Digital Factory, "Procedia CIRP" 2018, no. 72, pp. 179-184.

9 S. Peillon, N. Dubrue, Barriers to digital servitization in French manufacturing SMEs, "Procedia CIRP” 2019, no. 83, pp. 146-150. 
SMEs are lagging behind in digital innovation, its implementation process remains slow, and thus SMEs are at a risk of being left out of digital supply chains. SMEs also tend to have misconceptions about the complexity and costs of digitalization ${ }^{10}$.

\section{Challenges faced by agri-food and packaging SMEs}

The above challenges are especially present in agri-food and packaging, traditional industries that offer fast-moving consumer goods (FMCG) and are considered an important economic driver for many European regions. Demartini et al. ${ }^{11}$ states that currently, digitalization trends in food industry include internet of things (IoT), traceability, water management, big data or sustainability. Although the digitalization of the agrifood sector may provide many of benefits, it also brings several challenges, which have been subjects of different research studies. Rotz et al. ${ }^{12}$ focused on the technical and organisational challenges of digitalization in the agri-food sector. The application of digital and Industry 4.0 solutions in agri-food and packaging value chains is wide ranging - it can help to extend shelf life, monitor freshness, display information on quality, improve safety, and improve convenience. However, SMEs find it challenging to design new, digitalized business models adjusted to current economic realities. Moreover, they have problems in knowing which technology would be suitable for their business and how and where to find the right technology suppliers. These problems apply also to Polish SMEs; therefore, it is important to answer the following research question:

R1: What are the challenges faced by agri-food and packaging SMEs in the incorporation of digital innovations?

\section{Challenges faced by ICT SMEs}

Digital transformation is also challenging for those companies representing the information and communication technologies (ICT) industry that offer digital solutions for agri-food and packaging companies. According to Brewster et al., a key challenge for ICT implementation in the agriculture industry is information management related to heterogeneity and the sizeable number of actors along the supply chain ${ }^{13}$.

10 P. Kilimis et al., A Survey...

11 M. Demartini et al., Food industry digitalization: from challenges and trends to opportunities and solutions, "IFAC-PapersOnLine" 2018, no. 51(11), pp. 1371-1378.

12 S. Rotz et al., Automated pastures and the digital divide: How agricultural technologies are shaping labour and rural communities, "Journal of Rural Studies” 2019, no. 68, pp. 112-122.

13 C. Brewster, S. Wolfert, H. Sundmaker, Identifying the ICT challenges of the Agri-Food sector to define the Architectural Requirements for a Future Internet Core Platform, "Proceedings eChallenges e-2012" 2012, pp. 1-8. 
In addition, the potential applications of ICT solutions in agri-food and packaging are wide and varied, including, among others, software for supply chain or financial management, mobile applications for farm management, agricultural land use optimization, precision agriculture applications, all of which fall into categories of ICT-enabled services ${ }^{14}$. Another reason is connected to the location disparity between agri-food and ICT companies. Agri-food SMEs are often located in rural areas with poor internet infrastructure and insufficient power supply. A lack of awareness of the hi-tech solutions - especially among rural farmers, low level of digitalization of agri-food companies and low incomes of rural farmers, together with the high costs of ICT infrastructure, insufficient personnel to handle ICT facilities and the absence of content in local languages on the internet make digital transformation a challenge ${ }^{15}$. On the other hand, ICT companies are often located in urban areas, do not fully comprehend the technological needs of the agri-food sector and suffer from lack of knowledge on how to translate the benefits of digital solutions in an easy and understandable way. Therefore, another research question is proposed for exploration in this study:

R2: What are the challenges faced by ICT SMEs in providing solutions for digitalization of agri-food and packaging SMEs?

\section{New collaboration tools within Industry 4.0}

In order to stay competitive, absorb high quality know-how and gain access to external resources, facilities, infrastructures, and services, SMEs tend to collaborate with academic, private, public and non-governmental organisations to increase innovation in manufacturing processes. One of the ways of achieving such collaboration is by joining clusters which, according to Porter ${ }^{16}$, influence competitiveness by increasing the efficiency and productivity of companies, interconnecting scientific units, other enterprises and customers, and stimulating the formation of new businesses. Peillon and Dubrue ${ }^{17}$ argue that clusters could be of great help in supporting SMEs on their pathway toward digitisation in order to be able to build digital strategies.

There is also a growing need to help industry - including agri-food and packaging sectors - to develop innovative products that integrate different

14 M. Salampasis, A. Theodoridis, Information and Communication Technology in Agricultural Development Preface, "Procedia Technology" 2013, no. 8, pp. 1-3.

15 Ibidem.

16 M.E. Porter, Clusters and the new economics of competition, "Harvard Business Review" 1998, no. 76(6), pp. 77-90.

17 S. Peillon, N. Dubruce, Barriers to digital servitization... 
technologies. As innovation requires extensive collaboration between a diverse group of stakeholders from disparate fields ${ }^{18}$, being part of collaborative networks, such as clusters, stimulates the circulation of knowledge and the creation of new links between private, public, academic and business support organisations from given or connected sectors. As world history shows, great discoveries and most new ideas are achieved by identifying new connections between existing products and combining them in a novel way. This cross-sectoral and cross-industry approach is important to generate innovations which are mostly a recombination of existing knowledge ${ }^{19}$ and is likely to occur at the boundaries where different industries meet. According to Enkel and Gassman ${ }^{20}$, preexisting solutions from other industries are creatively imitated and retranslated in cross-industry innovation to meet the needs of a company's current market or products.

Taking into account today's turbulent business environment, characterized by rapid technological changes and increased globalization ${ }^{21}$, SMEs need agile methods to react quickly and flexibly to unexpected changes ${ }^{22}$ and to translate ideas and knowledge into marketable products and services in a fast and efficient way. This could be done by applying the co-creation concept defined by Roser et al. ${ }^{23}$ as an interactive, creative and social process between stakeholders that is initiated by companies at different stages of the value creation process. These co-creation activities are considered a form of collaborative innovation.

In recent years, the necessity for interdisciplinary teams to address concrete challenges has become more and more apparent, and hackathons are the answer. Hackathons are considered to be an emerging approach in supporting multidisciplinary innovation ${ }^{24}$, and are seen as an interdisciplinary experience where

18 U. Iqbal et al., A hackathon promoting Taiwanese health-IoT innovation, "Computer Methods and Programs in Biomedicine" 2018, vol. 163, pp. 29-32.

19 J.A. Schumpeter, Business Cycles: A Theoretical, Historical and Statistical Analysis of the Capitalist Process, McGraw-Hill, New York 1939.

20 E. Enkel, O. Gassmann, Creative imitation: exploring the case of cross-industry innovation, “R\&D Management" 2010, no. 40, pp. 256-270.

21 T. Mufudza, Dynamic Strategy in a Turbulent Business Environment, [in:] L.E. Okechukwu, Y.A. Hasan (eds), Strategic Management - a Dynamic View, IntechOpen, 2019, http://doi.org /10.5772/intechopen.81250

22 N. Niewöhner et al., Design fields of agile innovation management in small and medium sized enterprises, "Procedia CIRP" 2019, vol. 84. pp. 826-831.

23 T. Roser, R. DeFillippi, A. Samson, Managing your co-creation mix: Co-creation ventures in distinctive contexts, "European Business Review" 2013, no. 25(1), pp. 20-41.

24 U. Iqbal et al., A hackathon promoting... 
the knowledge and skills gained could be applied in real world settings ${ }^{25}$. Celi et al. ${ }^{26}$ define hackathons as intense, short, collaborative events focused on creating innovative solutions for pressing issues, where problems are solved in a limited time frame of 24-48h through intense participant collaboration ${ }^{27}$. The word 'hackathon' is the combination of two words, 'hack/hacking' and 'marathon', and was used for the first time for this purpose at a software engineering event. Currently, the concept of hackathons has been adapted by SMEs, large companies, public administrations, startups, scientific institutions and other organisations and communities interested in solving quickly-defined challenges or for working collectively on innovations. Taking into account the iterative approach of agile methods and their high flexibility, these tools could be particularly suitable for developments in times of rapid technological change and be used to boost crossindustry cooperation. Nevertheless, taking into account the limited time frame of these events, many challenges remain unsolved, as the participation process demands additional time for building the necessary trust. Moreover, the process of collaboration with a wide variety of stakeholders is a very intense and demanding one ${ }^{28}$. Taking into account the above, the following question is proposed for study:

R3: In what way can hackathons influence cross-industry collaboration concerning digital innovations in agri-food and packaging SMEs?

\section{Research method}

The research was concentrated on a single case encompassing the DIGICLUSTERS project financed by the European Union under the COSME Programme. In line with Yin ${ }^{29}$, the research was based on a number of different activities carried out between October 2018 and October 2019, which covered:

- a literature review;

- participant observation;

25 M.P. Lyndon et al., Hacking Hackathons: Preparing the next generation for the multidisciplinary world of healthcare technology, "International Journal of Medical Informatics" 2018, vol. 112, pp. 1-5.

26 L.A. Celi et al., Crowdsourcing knowledge discovery and innovations in medicine, "Journal of Medical Internet Research” 2014, no. 16(9), e216, https://doi.org/10.2196/jmir.3761

27 J.L. Zapico, D. Pargman, H. Ebner, E. Eriksson, Hacking sustainability: Broadening participation through Green Hackathons, Fourth international Symposium on End-User-Development, IT University of Copenhagen, Copenhagen, June 10-13, 2013.

28 K. Pogačar, A. Žižek, Urban Hackathon - Alternative Information Based and Participatory Approach to Urban Development, "Procedia Engineering" 2016, no. 161, pp. 1971-1976.

29 R.K. Yin, Case Study Research: Design and Methods, Sage, Thousand Oaks 2003. 
- summary of results of the CAWI - a survey based on a questionnaire provided to the agri-food, packaging, and ICT SMEs from Poland, Lithuania, Latvia, and Spain;

- collection of challenges gathered from cross-industry hackathons;

- summaries of evaluations from four regional cross-industry hackathons.

The research had an exploratory character, due to its novel topic and the lack of similar studies in this region of Europe. The studied companies were SMEs and members of seven European cluster organisations involved in the implementation of the DIGICLUSTERS project - a European Strategic Cluster Partnership for smart investment (ESCP-S3) aimed at speeding up the industrial modernisation of agrifood packaging sectors towards Industry 4.0, and digital transformation financed from the European Union under the COSME Programme (Table 1).

Table 1. Cluster organisations participating in the DIGICLUSTERS project

\begin{tabular}{|l|l|l|l|}
\cline { 2 - 4 } \multicolumn{1}{l|}{} & \multicolumn{1}{c|}{ Cluster organisation } & \multicolumn{1}{c|}{ Sector } & \multicolumn{1}{c|}{ Country } \\
\hline 1 & Latvian IT Cluster & ICT/IT & Latvia \\
\hline 2 & OnGranada Tech City & ICT/IT & Spain \\
\hline 3 & AgroBioCluster & Food & Poland \\
\hline 4 & Smart Food Cluster & Food & Lithuania \\
\hline 5 & Food Quality Products Cluster & Food & Latvia \\
\hline 6 & Lithuanian Printing Industries & Packaging & Lithuania \\
\hline 7 & Lithuanian Innovation Centre & ICT/IT & Lithuania \\
\hline
\end{tabular}

Source: own elaboration.

Table 2. CAWI study participants

\begin{tabular}{|c|l|c|}
\cline { 2 - 3 } \multicolumn{1}{c|}{} & \multicolumn{1}{c|}{ SMEs } & Number of questionnaires received \\
\hline 1 & Agri-food and packaging SMEs & 44 \\
\hline 2 & ICT SMEs & 45 \\
\hline TOTAL & 99 \\
\hline
\end{tabular}

Source: own elaboration.

Intelligence gathering within the hackathons included an online survey, interviews during the execution of four cross-industry hackathons, formal and informal meetings and online peer-reviews between project partners. One of the information gathering tools was the CAWI - survey, including two types of respondents: SMEs from the agri-food and packaging sector and SMEs from ICT/ Industry 4.0. The study took place between January and March 2019. The cluster organisations sent a link to the survey to their members and gathered 44 answers from agri-food and packaging firms and 45 from ICT SMEs, specifying, among 
others, the challenges faced in relation to digital transformation. The questionnaires were completed mostly by SMEs owners, managing directors, innovation specialists and export managers.

\section{Findings}

DIGICLUSTERS partnerships are focused on linking digital, hi-tech solutions with traditional industries (agri-food and packaging) with the goal of smoothing the way for innovations and ideas while overcoming any associated disruptive effects. In order to achieve this, the project was divided into three parts: preparation, implementation and sustainability. To identify the needs of SMEs in terms of digitalization and to stimulate the implementation of co-creation in digital innovations, several activities were undertaken by project partners parallelly in Poland, Latvia, Lithuania and Spain. These led to the identification of the concrete challenges faced by agri-food, packaging and ICT SMEs in their digital transformation towards Industry 4.0.

\section{Challenges faced in relation to the incorporation of digital solutions by SMEs from the agri-food and packaging sector}

Although agri-food and packaging companies agree that their competitiveness is dependent upon the implementation of technological solutions - especially automation, sensor and wireless technologies - they encounter several challenges in their digital transformation. One of which is linked to keep up with the fast emergence of new technologies, especially those related to virtualization/simulation, robotics, blockchains, machine learning/artificial intelligence and augmented reality. They find the technological language difficult to understand, as the ICT sector tends to communicate their solutions in terms of technological features and not in terms of benefits for solving specific problems. In addition, the lack of previous experience in the digitalization and innovation process and the poor digital capabilities are considered barriers that are especially experienced by companies based in rural areas. SMEs highlighted that they have difficulties in finding the right technology suppliers to solve their problems. The technological challenges that the Agri-food and packaging companies reported include those that dealt with the virtual management of the production process, electronic document flow, B2B platforms, smart visual quality control, online customer support or the need of behavioral and predictive analysis.

The companies also highlighted the lack of meeting places where agri-food, packaging and ICT industries could discuss their needs and find related solutions. The 
lack of knowledge about existing innovation networks or clusters that provide digital solutions was also presented as another important bottleneck in the implementation of digital innovations. Agri-food and packaging companies are aware that these challenges make them less competitive and innovative when considering expansion at European or international level. The companies also have a low evaluation of their own competences, which makes them reticent to engage in new projects.

\section{Challenges faced by SMEs from the ICT sector}

ICT companies also face several challenges in relation to the digitalization of agri-food and packaging SMEs. The first and foremost bottleneck is lack of experience, as most ICT companies have not collaborated with companies from the agri-food and packaging sector. This absence of customer orientation, together with a lack of communication skills and awareness of a client's needs reduce the possibilities of successfully identifying problems, and, as a consequence, the possibilities of providing the right technological solutions for agri-food and packaging companies. According to ICT SMEs, financial barriers are also considered obstacles in implementing digital solutions, since agri-food and packaging companies are often dealing with limited financial resources. ICT companies also highlighted the lack of access to agri-food networks and other associations as a barrier to implementing solutions in the value chain.

\section{Tools applied in collaboration}

With the goal of resolving some of these challenges and to facilitate collaboration, the project partners adapted the concept of hackathons designed to stimulate cross-sectoral, cross-border and cross-cluster cooperation between high-tech (digital innovation hubs - DIH), biotech and ICT) and traditional (agro, food \& packaging) clusters and their members. The main beneficiaries in the process of applying digital solutions to agri-food and packaging were expected to be SMEs. Thus, four cross-industry regional hackathons - one in each participating country - took place between April and October 2019.

All of the mentioned events included a staged experimentation process called XIndustry Hackathons that promoted the incorporation of innovation drivers: Industry 4.0 and digital solutions to food \& packaging sectors to improve productivity, better flexibility, agility, and increase profitability. The main process included collecting the cases where implementation challenges were faced by agri-food and packaging companies, the search for IT solutions and preparing the logistic and technical organisation of hackathons. Taking into account the different business environment, territorial and organisational potential, each participating country adapted the concept of hackathons to their regional needs and available timeframe. 
Table 3. DIGICLUSTERS cross-industry hackathons

\begin{tabular}{|c|c|c|c|}
\hline & Clusters involved & Place & Date \\
\hline \multirow{2}{*}{1} & Latvian IT Cluster & \multirow{2}{*}{ Riga (Latvia) } & \multirow{2}{*}{ March - April 2019} \\
\hline & Food Quality Products Cluster & & \\
\hline 2 & AgroBioCluster & Warsaw (Poland) & April - October 2019 \\
\hline \multirow{3}{*}{3} & Smart Food Cluster & \multirow{3}{*}{ Vilnius (Lithuania) } & \multirow{3}{*}{ June - October 2019} \\
\hline & Lithuanian Printing Industries & & \\
\hline & Lithuanian Innovation Centre & & \\
\hline 4 & OnGranada Tech City & Granada (Spain) & September - October 2019 \\
\hline
\end{tabular}

Source: own elaboration.

The companies from agri-food, packaging and ICT sectors highlighted their interest in cooperation with companies from Lithuania, Latvia, Poland and Spain as they believed that cross-industry collaboration with ICT companies would increase their competitiveness in both local and international markets. They expressed the necessity to identify real business collaboration opportunities, facilitate communication between traditional industries and technologically advanced ones, and to engage in joint activities, concerning cross-industry and cross-border collaboration between clusters, ICT and agri-food and packaging enterprises.

During these regional hackathons cross-industry teams worked on different challenges related to the incorporation of both incremental digital innovations (for instance, digitalization of company documents) or disruptive technologies (for instance, related to the application of artificial intelligence in production processes.

The cluster organisations were as having the key role of promoters and facilitators (Figure 1), creating a collaborative workspace for agri-food, packaging and ICT companies.

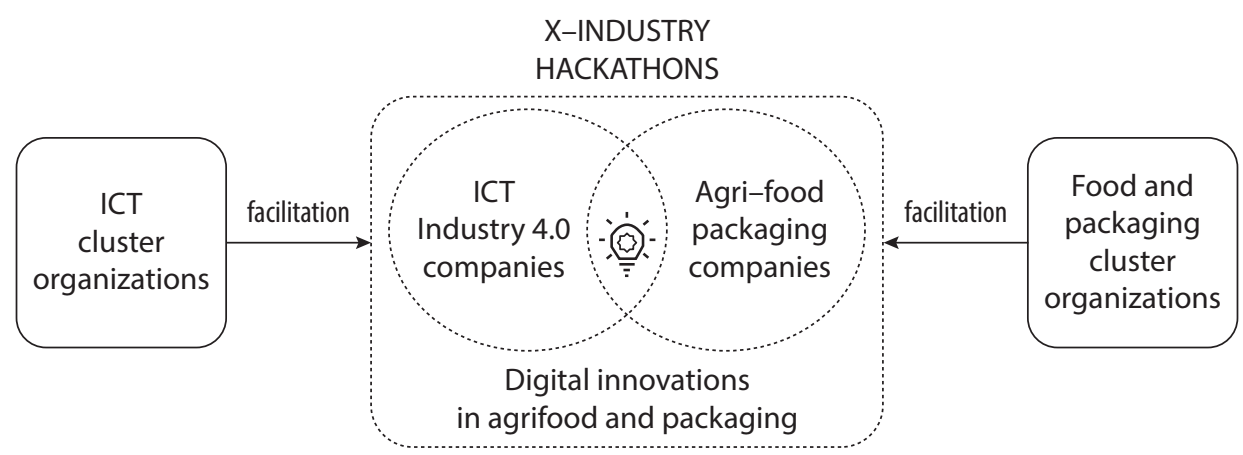

Figure 1. Role of actors participating in hackathons to stimulate innovations

Source: own elaboration. 
The cluster organisations' role also includes sharing information about international markets and stimulating international activities for their members, for instance by organising trade missions, international networking, establishing new contacts or performing market research.

\section{Conclusions}

The agri-food, packaging and ICT companies that belong to European clusters face several technological, financial and managerial challenges on their way to digital transformation. Primarily, they need help in incorporating digital solutions, technological updates, and tools in their business processes to satisfy customers' needs and demands. These technological solutions can be provided by ICT companies in order to modernize products and services and enhance productivity.

This case study has shown that the most important challenges include technological, organisational and human resource-oriented barriers, which is in-line with the studies of Peillon and Dubrue ${ }^{30}$. In the context of B2B relations, ICT firms play a supportive role in providing digital solutions to value chain companies of the agri-food and packaging sector. As the process is complex and the FMCG environment highly dynamic and competitive, challenges are also faced connected with lack of experience, poor contact with agri-food and packaging companies, financial limitations and insufficient digital competences among agri-food companies and limited venues and opportunities to network and establish new contacts. The most important challenges are in line with the technical and organisational challenged described by Peillon and Dubrue.

As for the third research question - the role of hackathons is:

- to interconnect different stakeholders and create a dynamic environment that encourages cross-industry collaboration;

- to stimulate the creation of new ideas, concepts and prototypes by combining SMEs' competences;

to support the generation of incremental and radical innovations related to digital innovations in agri-food and packaging.

The study showed that, among these many functions, hackathons most effectively promote new contacts, match companies and stimulate their collaboration in digital transformation. However, the introduction of these new collaboration tools also poses several challenges, which relate to the time needed for organisation and the skills necessary to build trust and engagement of between a wide variety of different stakeholders. Such tools have only recently begun to be implemented and, thus,

30 S. Peillon, N. Dubrue, Barriers to digital servitization... 
there is a need to continue the research on cross-industry cooperation and on the application of such agile tools for the development of innovations.

\section{Limitations and future research}

Although this article covers an existing gap in the literature, it also has several limitations that may serve as an inspiration for future research. First, the results draw on a sample of agri-food, packaging and ICT companies, hence the findings might be industry specific. Therefore, future studies should explore this topic in different industries. In addition, the method is qualitative and could be supplemented with additional quantitative analysis of similar tools or the experience of other European clusters.

\section{References}

Brewster C., Wolfert S., Sundmaker H., Identifying the ICT challenges of the Agri-Food sector to define the Architectural Requirements for a Future Internet Core Platform, "Proceedings eChallenges e-2012" 2012, pp. 1-8.

Celi L.A., Ippolito A., Montgomery R.A., Moses C., Stone D.J., Crowdsourcing knowledge discovery and innovations in medicine, "Journal of Medical Internet Research" 2014, no. 16(9), e216, https://doi.org/10.2196/jmir.3761

Chukwunonso F., Tukur A., Problems and prospects of adopting ICT in agriculture, "African Journal of Agricultural Research and Development" 2012, no. 5, pp. 39-47.

Demartini M., Pinna C., Tonelli F., Terzi S., Sansone C., Testa C., Food industry digitalization: from challenges and trends to opportunities and solutions, "IFAC-PapersOnLine" 2018, no. 51(11), pp. 1371-1378.

EASME, Annual Report on European SMEs 2018/2019, European Commission, Brussels 2019.

Enkel E., Gassmann O., Creative imitation: exploring the case of cross-industry innovation, "R\&D Management" 2010, no. 40, pp. 256-270.

Iqbal U., Dagan A., Syed-Abdul S., Celi L.A., Hsu M.-H., Li Y.-C.J., A hackathon promoting Taiwanese health-IOT innovation, "Computer Methods and Programs in Biomedicine" 2018, vol. 163, pp. 29-32.

Kilimis P., Zou W., Lehmann M., Berger U., A Survey on Digitalization for SMEs in Brandenburg, Germany, "IFAC-PapersOnLine" 2019, no. 52(13), pp. 2140-2145.

Lyndon M.P., Cassidy M.P., Celi L.A., Hendrik L., Kim Y.J., Gomez N., Baum N., Bulgarelli L., Paik K.A., Dagan A., Hacking Hackathons: Preparing the next generation for the multidisciplinary world of healthcare technology, "International Journal of Medical Informatics" 2018, vol. 112, pp. 1-5.

Mufudza T., Dynamic Strategy in a Turbulent Business Environment, [in:] L.E. Okechukwu, Y.A. Hasan (eds), Strategic Management - a Dynamic View, IntechOpen, 2019, http://doi .org/10.5772/intechopen.81250

Niewöhner N., Asmar L., Wortmann F., Röltgen D., Kühn A., Dumitrescu R., Design fields of agile innovation management in small and medium sized enterprises, "Procedia CIRP" 2019, vol. 84. pp. 826-831. 
Peillon S., Dubrue N., Barriers to digital servitization in French manufacturing SMEs, "Procedia CIRP" 2019, no. 83, pp. 146-150.

Pogačar K., Žižek A., Urban Hackathon - Alternative Information Based and Participatory Approach to Urban Development, "Procedia Engineering” 2016, no. 161, pp. 1971-1976.

Porter M.E., Clusters and the new economics of competition, "Harvard Business Review" 1998, no. 76(6), pp. 77-90.

Roser T., DeFillippi R., Samson A., Managing your co-creation mix: Co-creation ventures in distinctive contexts, "European Business Review" 2013, no. 25(1), pp. 20-41.

Rotz S., Gravely E., Mosby I., Duncan E., Finnis E., Horgan M., LeBlanc J., Martin R., Tait Neufeld H., Nixon A., Pant L., Shalla V., Fraser E., Automated pastures and the digital divide: How agricultural technologies are shaping labour and rural communities, "Journal of Rural Studies" 2019, no. 68, pp. 112-122.

Salampasis M., Theodoridis A., Information and Communication Technology in Agricultural Development Preface, "Procedia Technology" 2013, no. 8, pp. 1-3.

Schallmo D., Williams C., Boardman L., Digital Transformation of Business Models-Best Practice, Enabler, and Roadmap, "International Journal of Innovation Management" 2018, no. 21(8), pp. 1-17.

Schumpeter J.A., Business Cycles: A Theoretical, Historical and Statistical Analysis of the Capitalist Process, McGraw-Hill, New York 1939.

Stoldt J., Trapp T.U., Toussaint S., Süße M., Schlegel A., Putz M., Planning for Digitalisation in SMES using Tools of the Digital Factory, "Procedia CIRP" 2018, no. 72, pp. 179-184.

Ulas D., Digital Transformation Process and SMEs, "Procedia Computer Science” 2019, no. 158, pp. 662-671.

Yin R.K., Case Study Research: Design and Methods, Sage, Thousand Oaks 2003.

Zapico J.L., Pargman D., Ebner H., Eriksson E., Hacking sustainability: Broadening participation through Green Hackathons, Fourth international Symposium on End-User-Development, IT University of Copenhagen, Copenhagen, June 10-13, 2013.

Zezulka F., Marcon P., Vesely I., Sajdl O., Industry 4.0 - An Introduction in the phenomenon, "IFACPapersOnLine" 2016, no. 49(25), pp. 8-12.

\section{Abstract}

The article presents exploratory research that is aimed at identifying the challenges existing in the process of stimulating cross-industry collaboration between European agri-food, packaging and ICT SMEs in their digital transformation towards Industry 4.0. Taking as an example the European Strategic Cluster Partnership for smart investments called DIGICLUSTERS, the article presents qualitative research based on a single case study. The case examines a cluster-facilitated, agile approach to speeding up the prototyping and implementation of digital innovations in agri-food and packaging companies. Within this framework, the article shows that fostering cross-industry cooperation between traditional and hi-tech companies operating in clusters brings several benefits, but also entails technological, financial and managerial challenges. The originality of this article is in its examination of cross-industry hackathons as a new collaboration tool to stimulate digital innovations in agri-food and packaging SMEs towards Industry 4.0.

Keywords: SMEs, management challenges, digitalisation, hackathons, cross-industry collaboration, Industry 4.0, clusters 